\title{
Short Commons for Canadians
}

\section{from our Special Correspondent}

\section{Ottawa, September $26^{\circ}$}

THE enthusiasm for balancing the Canadian budget which has seized the Government of Mr Pierre Trudeau has provided some shocks for Canadian scientists. Last week the Federal Government announced the cancellation of two major projects, and followed this week with the publication of sharply reduced figures for government grants to science. The saddest are the astronomers, who have lost for the time being at least the plan to build a 150 inch telescope at Mount Kobau. At the same time, the plan for an intense neutron generator has also been deferred, and it is not clear whether it will ever be built.

The tendency in Ottawa is to dismiss the cuts as inevitable, even salutary. Attitudes among astronomers and high energy physicists are harder to gauge, because neither the telescope nor the neutron generator had unanimous support. The intense neutron generator, or ING, was a project which originated in the laboratories of Atomic Energy of Canada Ltd. The design provided for a machine one mile long in which protons would have been accelerated to the equivalent of one thousand million volts, before striking a lead/bismuth target to produce very fast neutrons. The generator was to have been used for chemical studies of the heavy elements, activation analysis, radiation chemistry and for providing data about the behaviour of fast neutrons which might have been useful for the design of fast breeder reactors. The Science Secretariat carried out a study of the project, and suggested that ING would indeed be worth the $\$ 155$ million it was expected to cost, an opinion which conflicted with those held in Canadian industry. (According to a survey by the Department of Industry, Canadian business "saw little opportunity for a continuing market outside the field of nuclear physics arising from ING".)

The opinion in Ottawa is that although the project was sound enough technically and worthy enough scientifically, too little effort had been made by Atomic Energy of Canada Ltd to interest the rest of the scientific community. Dr O. M. Solandt, chairman of the Science Council of Canada, criticizes AECL by saying that "they have not been very open in letting outsiders use other facilities at the Chalk River Laboratory". This, he suggests, has meant that the ING proposal has failed to gain overwhelming support in the universities. The Hon. C. M. Drury, president of the Treasury Board, says that the decision is a deferment rather than a cancellation, and suggests that it may well be possible to build ING in perhaps five years. He seems doubtful whether the machine could in any case have been built for $\$ 155$ million, and says that it would have done nothing for the immediate teaching problems in physies. The Tri-University Meson Facility (which now involves at least four universities) has been funded by the federal government, and will be built. It is not, however, on quite the same scale as ING and will cost a mere $\$ 19$ million.

Many of the same arguments are used to defend the cancellation of the Queen Elizabeth II telescope. This project would have cost $\$ 20$ million, and $\$ 4$ million has already been spent. Dr Solandt points out that the telescope would have appealed primarily to astronomers in Canadian government institutions, most of whom do their work within Canada. University astronomers, Dr Solandt says, would much prefer Canada to buy a share in the telescope being built with American money in Chile, chiefly because Mount Kobau in British Columbia is not a particularly favourable site. Experience with a 16 inch telescope there does not seem to have been encouraging. The result is that the Government has seized on the Queen Elizabeth II as the target for its enthusiastic cost cutting. In this case, there is no official optimism that the project can be saved, although there is a suggestion that several of the universities in the west might club together and raise the money without government support. If this can be done, the Federal Government would, of course, be only too happy.

The Government has followed up these two substantial cuts by lopping $\$ 2$ million off research grants for 1968-69. The Medical Research Council has been provided with a budget of $\$ 26,943,000$, more than $\$ 0.5$ million less than the earlier estimate, and the National Research Council has had some $\$ 1.5$ million taken from its initial estimate of $\$ 60,589,000$. The new budget also reduces the estimates of grants from the health resources fund, which comes down to $\$ 37.5$ million from $\$ 40$ million. Grants for improving technology in industry - a major theme among official spokesmen here--will also be held within a lower limit, $\$ 10$ million instead of $\$ 15$ million.

To an observer used to crises of British dimensions, it is hard to see why all this self-imposed restraint is necessary. The real reason seems to be that government spending has been increasing at a rate which Canadians find frightening, in part at least because welfare and health programmes entered into a few years ago are now beginning to cost money. Educational building has also been going on at an impressive rate. The way in which the programmes are designed also seems to include a degree of built-in escalation, and the bill the Federal Government has to pay covers some commitments entered into by the provincial governments. Hence the rate of expenditure has been rising more rapidly than the ability to pay. Because Canadians already regard themselves as heavily taxed, the alternative of raising taxes would be unpopular. It may, however, prove to be necessary. Despite the reductions made in the attempt to balance the budget (more than $\$ 80$ million worth of expenditure has been cut from estimates published in February) federal spending has burst through the limits. An increase of $\$ 433$ million has been recorded, mostly for reasons outside the Cabinet's immediate controlpayments to the provinces, debt charges and the first charges for medical care insurance. This means that Finance Minister E. J. Benson will either have to find room for more cuts or raise taxes if he is to keep to his aim of producing a balanced budget this year. 